T. 2, № 1, 2020

УДК 621.313.823

Б. М. Харчишин

Національний університет “Львівська політехніка", кафедра електромехатроніки та комп'ютеризованих електромеханічних систем, Bohdan.M.Kharchyshyn@lpnu.ua

М. В. Хай

Національний університет “Львівська політехніка”, кафедра електромехатроніки та комп'ютеризованих електромеханічних систем, mxaishk@gmail.com

Б. Г. Бойчук

Національний університет “Львівська політехніка”, кафедра електромехатроніки та комп'ютеризованих електромеханічних систем,

b_boychuk@meta.ua

М. М. Радович

Національний університет "Львівська політехніка", студент ЕE-22 (IECK), Mykhailo.M.Radovych@1pnu.ua

\title{
ОСНОВНІ КОНСТРУКТИВНІ СПІВВІДНОШЕННЯ ЛІНІЙНОГО ГЕНЕРАТОРА ІМПУЛЬСНОЇ ДІЇ
}

https://doi.org/10.23939/sepes2020.01.088

(C) Харчишин Б. М., Хай М. В., Бойчук Б. Г., Радович М. М., 2020

Проаналізовано види втраченої при артилерійському пострілі енергії 3 метою визначення можливості її повторного використання. Пропонується використати кінетичну енергію руху ствола і противідкотних пристроїв для генерування та акумулювання у вигляді електричної енергії для підвищення енергетичної незалежності підрозділу при виконанні бойової задачі.

Для цієї мети застосовано лінійний генератор імпульсної дії з гладким якорем магнітоелектричного збудження, структуру активної частини якого досліджено.

Застосовано принципи поділу структури електромеханічного перетворювача до лінійного генератора імпульсної дії, що дозволило оптимально використовувати активні матеріали.

Використано твердження, що при ненасиченому магнітопроводі магніторушійна сила постійного магніту прикладена в основному до немагнітного проміжку, тому за основний критерій проектування взято рівність висоти магніту величині, що складасться 3 товщини обмоткового шару та технологічного проміжку між магнітом та 
Обмоткою, а товщина активної зони дорівнює сумарній товщині спинок магнітопроводів статора і повзуна.

Встановлено оптимальні значення величини полюсної поділки для заданих значень внутрішнього та зовнішнього габаритного діаметрів проектованого генератора.

Наведено основні співвідношення для визначення оптимальних значень ширини та висоти магніту, товщини спинок магнітопроводу статора та повзуна з урахуванням коефіцієнтів розсіяння та приведення площі магнітопроводу до середнього його діаметра, який враховус зменшення площі магнітопроводу через зменшення діаметра порівняно з внутрішнім діаметром магніту.

Подано співвідношення для визначення діаметра розточки повзуна.

Ключові слова: лінійний генератор; кільцевий постійний магніт; котушка; кільцева обмотка; повзун; товщина магнітопроводу повзуна; магнітопровід статора; індуктор.

\section{Вступ}

У сучасних умовах ведення бойових дій за участю артилерійського озброєння актуальним стало збільшення енергетичної незалежності артпідрозділу. Тоді як кожен постріл супроводжується розсіюванням більшої частини енергії, доцільним $є$ перетворення ії на електричну з подальшим акумулюванням та зберіганням для потреб підрозділу при виконанні бойової задачі. Джерелом енергії, яка втрачається під час пострілу, є кінетична енергія лінійного руху стволу та противідкотних пристроїв, нагрівання стволу, дисипація порохових газів в атмосферу тощо $[1,2]$. Перетворення першого з них розглянуто в цій статті.

Аналіз останніх досліджень і постановка задачі.

Сучасний підхід до проектування електричних машин базується на відомому співвідношенні

$$
M=\frac{1}{2 \pi}\left(\Phi_{\Sigma}\right) \times\left(I_{\Sigma}\right) \quad \text { або } \quad M=\frac{1}{2 \pi} \times(\tilde{B} \delta \times j) \times\left(S_{\varphi} \cdot S_{M}\right),
$$

де $M$ - електромагнітний момент; $\Phi_{\Sigma}-$ сумарний магнітний потік;

$I_{\Sigma}-$ сумарний струм якоря; $\tilde{B}_{\delta}-$ середня індукція у повітряному проміжку, Тл; $j$ - ефективна густина струму у провідниках якоря, $\mathrm{A} /$ мм $^{2} ; S_{M}$ - сумарна площа поперечного перетину провідників якоря, мм ${ }^{2} ; S_{\varphi}$ - сумарна площа полюсів (магнітів) індуктора ЕМП, $\mathrm{m}^{2}$.

Це дає змогу замість машинної сталої Арнольда застосовувати добуток $\tilde{B}_{\delta} \times j$ із значно меншою варіацією. На рис. 1 показано структуру електромеханічного перетворювача в уніполярному його виконанні. Поділ структури дає змогу перейти до багато-

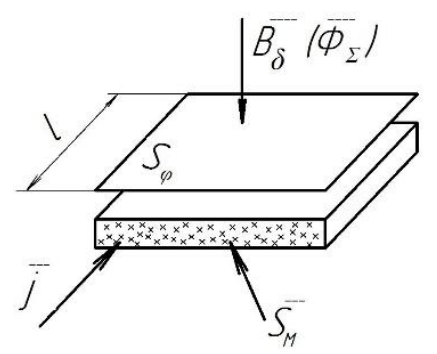

Рис. 1. Структура уніполярного електромеханічного перетворювача полюсної структури і використати ії переваги [3-6] (рис. 2).
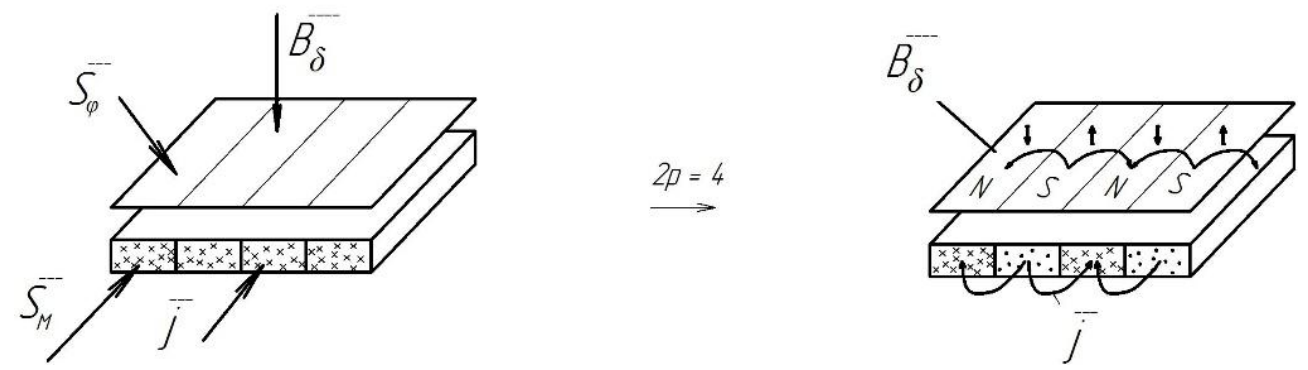

Рис. 2. Поділ структури на прикладі 4-полюсного перетворювача 


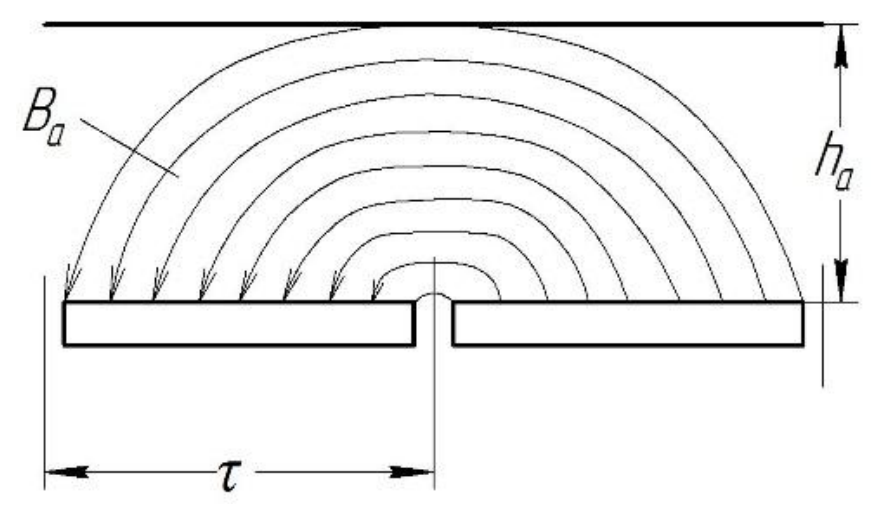

Рис. 3. Структура індуктора електромеханічного перетворювача

Зважаючи, що в таких конструкціях, як машина постійного струму, електронно-керований двигун, моментний двигун тощо ми можемо вибирати кількість пар полюсів на свій розсуд, виникає спокуса зменшення величини полюсної поділки $\tau$, тобто збільшення кількості пар полюсів $p$ за заданого габариту задля зменшення товщини ярма $h_{a}$ індуктора (рис. 3), довжини лобових частин, а, відповідно, і масо-габаритних показників.

Отже, перед авторами постала задача адаптувати відому конструкцію лінійної електричної машини $[7,8]$ до використання іï в режимі генератора імпульсної дії артилерійської установки з використанням викладених вище принципів поділу структури електромеханічного перетворювача.

\section{Завдання дослідження}

Завданням цього дослідження є створення основних підходів будови та конструктивних співвідношень лінійних генераторів імпульсної дії.

\section{Об'єкт досліджень}

Об'єктом досліджень у цій статті є структура активної частини лінійного генератора імпульсної дії.

\section{Виклад основного матеріалу.}

Враховуючи, що за ненасиченого магнітопроводу магніторушійну силу постійного магніту прикладено в основному до немагнітного проміжку $\Delta$, приймемо за основний критерій проектування рівність висоти магніту $h_{m}$ величині $\Delta$, що складається 3 товщини обмоткового шару та технологічного проміжку $\delta$ між магнітом та обмоткою $\left(\Delta=h_{p}+\delta\right)$.

Крім того, товщина активної зони дорівнює сумарній товщині спинок магнітопроводів статора $h_{s t}$ і повзуна $h_{p}$

$$
h_{m}+\Delta=h_{s t}+h_{p}=\frac{D_{z}-D_{v}}{4}
$$

звідки

$$
h_{m}=\frac{D_{z}-D_{v}}{8},
$$

де $D_{z}$ і $D_{v}$-зовнішній та внутрішній габаритний діаметр лінійного генератора.

3 досвіду проектування електричних машин 3 постійними магнітами [5] відомо, що задля уникнення значних потоків розсіяння потрібно ширину висококоерцитивного постійного магніту $b_{m}$ вибирати не меншою за дві його висоти. Для зменшення частоти перемагнічування магнітопроводу статора полюсна поділка $\tau$ та ширина магніту повинні бути збільшені $b_{m} \geq 3,5 \cdot h_{m}$.

Оптимальна величина полюсного перекриття (відносна ширина магніту виражена у полюсних поділках $\tau) \quad \alpha=b_{m} / \tau$ з тієї ж причини становить $0,75 \ldots 0,85$. 


\section{Основні конструктивні співвідношення лінійного генератора імпульсної дї}

Товщина спинки магнітопроводу повзуна пропорційна до площі магніту і визначається за рівнянням

$$
h_{p}=\frac{b_{m}}{2 K_{p m}} \cdot K,
$$

де $K_{p m}-$ коефіцієнт, що враховує відношення магнітної індукції в магнітопроводі повзуна до індукції в магніті $\left(K_{p m} \approx 2\right) ; K=\frac{D_{v}+2 h_{p}}{D_{v}+h_{p}}-$ коефіцієнт приведення площі магнітопроводу до середнього його діаметра, який враховує зменшення площі магнітопроводу через зменшення діаметра порівняно з внутрішнім діаметром магніту.

Отже,

$$
h_{p}=\frac{b_{m}}{2 K_{p m}}-\frac{D_{v}}{2}+\sqrt{\left(\frac{D_{v}}{2}\right)^{2}+\left(\frac{b_{m}}{4}\right)^{2}},
$$

як додатний корінь відповідного квадратного рівняння.

Товщина спинки магнітопроводу статора $h_{s t}$ визначається із співвідношення площ перетину магнітопроводів статора і повзуна, через які проходить робочий і повний магнітні потоки відповідно

$$
\frac{S_{s t}}{S_{p}}=\frac{\left(D_{z}-h_{s t}\right) \cdot h_{s t}}{\left(D_{v}+h_{p}\right) \cdot h_{p}}=K_{\sigma},
$$

де $K_{\sigma}-$ коефіцієнт розсіяння, що дорівнює відношенню потоків у магнітопроводах статора $\mathrm{i}$ повзуна (зазвичай $K_{\sigma} \approx 0,9$ )

Отже,

$$
h_{s t}=\frac{D_{z}}{2}-\sqrt{\left(\frac{D_{z}}{2}\right)^{2}-K_{\sigma}\left(D_{v}+h_{p}\right) \cdot h_{p}}
$$

як менший корінь відповідного квадратного рівняння.

За визначеними величинами можна встановити діаметр розточки повзуна

$$
d=D_{v}+2\left(h_{p}+h_{m}\right)
$$

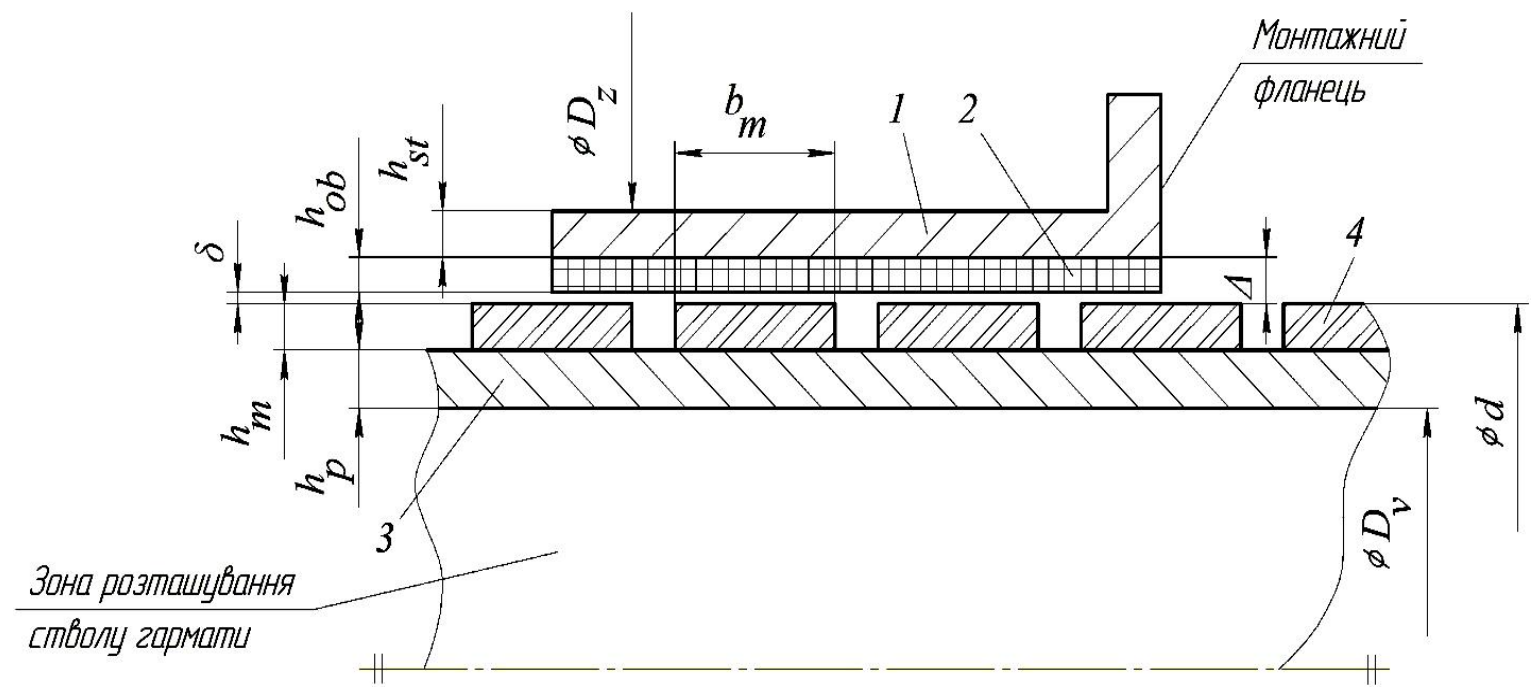

Рис. 4. Аксіальний переріз активної частини лінійного генератора 


\section{Б. М. Харчишин, М. В. Хай, Б. Г. Бойчук, М. М. Радович}

\section{Висновки}

1. Обгрунтовано можливість повторного використання кінетичної енергії лінійного руху ствола гармати.

2. Запропоновано для цього використати лінійний генератор магнітоелектричного збудження 3 гладким порожнистим якорем циліндричного виконання.

3. Проведені дослідження дали змогу оптимально за критерієм максимуму потужності поділити структуру активної частини лінійного генератора і вивести основні конструктивні співвідношення для визначення основних його розмірів за заданими зовнішнім та внутрішнім габаритним діаметром.

4. Питання оцінки гальмівного зусилля генератора на відкотні частини та оцінки відібраної перетвореної і акумульованої потужності стане напрямом подальших досліджень.

\section{Список використаних джерел}

1. Шабатура Ю. В. Підвищення бойових можливостей артилерійських підрозділів за рахунок застосування альтернативних джерел живлення / Ю. В. Шабатура, М. В. Баландін // Збірник наукових праць ЖВI "Проблеми створення, випробування, застосування та експлуатаџії складних інформаційних систем". 2017. № 14. C. 31-41.

2. Шабатура Ю. В. Комплексна система перетворення енергї, щуо розсіюється під час пострілу артилерійської гармати / Ю. В. Шабатура М. В. Баландін // Матеріали всеукраӥнської науково-технічної конферениії “Актуальні проблеми проектування, виготовлення $і$ експлуатації озброєння та військової техніки” 17-19 травня 2017 р.: збірник тез доповідей. Вінниия: ВНТУ. 2017. С. 336-339.

3. Pyrhönen Juha. Design of rotating electrical machines / Juha Pyrhönen, Tapani Jokinen, Valéria Hrabovcová ; translated by Hanna Niemel"a. p. cm. Includes bibliographical references and index. ISBN 978-0-47069516-6 (cloth) (C) 2008 John Wiley \& Sons, Ltd. 512 p.

4. Boldea I. The electric generators handbook. Synchronous generators / I. Boldea, CRC/Taylor \& Francis. 2006. $444 c$.

5. Gieras J. F. Permanent magnet motor technology: design and applications / J. F. Gieras, Third edition. CRC Press. London, New York. 2010. 603 c.

6. Попічко В. В. Проектування електричних машин постійного струму: навч. посіб. для студ. вищ. навч. закл./Нач. ун-т “Львів. політехніка”. Львів: Вид-во Нац. ун-ту “Львів. політехніка”, 2004.584 с.

7. Kharchyshyn B. Reduction of force ripples in linear motors / Bohdan Kharchyshyn, Mykhailo Khai, Volodymyr Moroz // Computational Problems of Electrical Engineering. 2014. Vol. 4. No. 1. P. 7-10.

8. Мороз В. I. Експериментальні дослідження динамічних властивостей лінійного двигуна 3 постійними магнітами / В. І. Мороз, П. А. Болкот, К. І. Снітков, Б. М. Харчишин // Наукові праці Донецького національного технічного університету. Серія “Електротехніка та енергетика”. 2013. № 2(15). С. 186-189.

9. Баландін М. В., Хай М. В., Харчишин Б. М., Цімко О. О. Лінійний генератор імпульсної дії. Заявка на видачу патенту на винахід. Реєстр. № а201901663 від 18.02.2019 p.

\section{References}

1. Shabatura Yu. V. Pidvy'shhennya bojovy’x mozhly vostej arty'lerijs ky’x pidrozdiliv za raxunok zastosuvannya al 'ternaty vny'x dzherel zhy vlennya / Yu. V. Shabatura, M. V. Balandin // Zbirny 'k naukovy’x pracz' ZhVI "Problemy`stvorennya, vy probuvannya, zastosuvannya ta ekspluataciyi skladny`x informacijny’x sy stem”. 2017. \# 14. S. 31-41.

2. Shabatura Yu. V. Kompleksna sy'stema peretvorennya energiyi, shho rozsiyuyet sya pid chas postrilu arty lerijs koyi garmaty' / Yu. V. Shabatura M. V. Balandin // Materialy 'vseukrayins koyi naukovo-texnichnoyi konferenciyi "Aktual ni problemy 'proektuvannya, vy gotovlennya i ekspluataciyi ozbroyennya ta vijs 'kovoyi texniky" 17-19 travnya 2017 r.: zbirny `k tez dopovidej. Vinny ‘cya: VNTU. 2017. S. 336-339. 
3. Pyrhönen Juha. Design of rotating electrical machines / Juha Pyrhönen, Tapani Jokinen, Valéria Hrabovcová; translated by Hanna Niemel"a. p. cm. Includes bibliographical references and index. ISBN 978-0-47069516-6 (cloth) (C) 2008 John Wiley \& Sons, Ltd. 512 p.

4. Boldea I. The electric generators handbook. Synchronous generators / I. Boldea, CRC/Taylor \& Francis. 2006. $444 c$.

5. Gieras J. F. Permanent magnet motor technology: design and applications / J. F. Gieras, Third edition. CRC Press. London, New York. 2010. 603 c.

6. Попічко В. В. Проектування електричних машин постійного струму: навч. посіб. для студ. вищ. навч. закл. / Наи. ун-т “Львів. політехніка". Львів: Вид-во Нац. ун-ту “Львів. політехніка”, 2004 . 584 с.

7. Kharchyshyn B. Reduction of force ripples in linear motors / Bohdan Kharchyshyn, Mykhailo Khai, Volodymyr Moroz // Computational Problems of Electrical Engineering. 2014. Vol. 4. No. 1. P. 7-10.

8. Moroz V. I. Ekspery 'mental 'ni doslidzhennya dy 'namichny'x vlasty vostej linijnogo dvy 'guna z postijny 'my' magnitamy' / V. I. Moroz, P. A. Bolkot, K. I. Snitkov, B. M. Xarchy`shy'n // Naukovi praci Donecz kogo nacional nogo texnichnogo universy tetu. Seriya "Elektrotexnika ta energety 'ka". 2013. \#2(15). S. 186-189.

9. Balandin M. V., Xaj M. V., Xarchy shy 'n B. M., Cimko O. O. Linijny j̈ generator impul snoyi diyi. Zayavka na vy'dachu patentu na vy'naxid. Reyestr. \# a201901663 vid 18.02.2019r.

B. Kharchyshyn,

Lviv Polytechnic National University, Department of Electromechatronics and Computerized Electromechanical Systems

Bohdan.M.Kharchyshyn@lpnu.ua

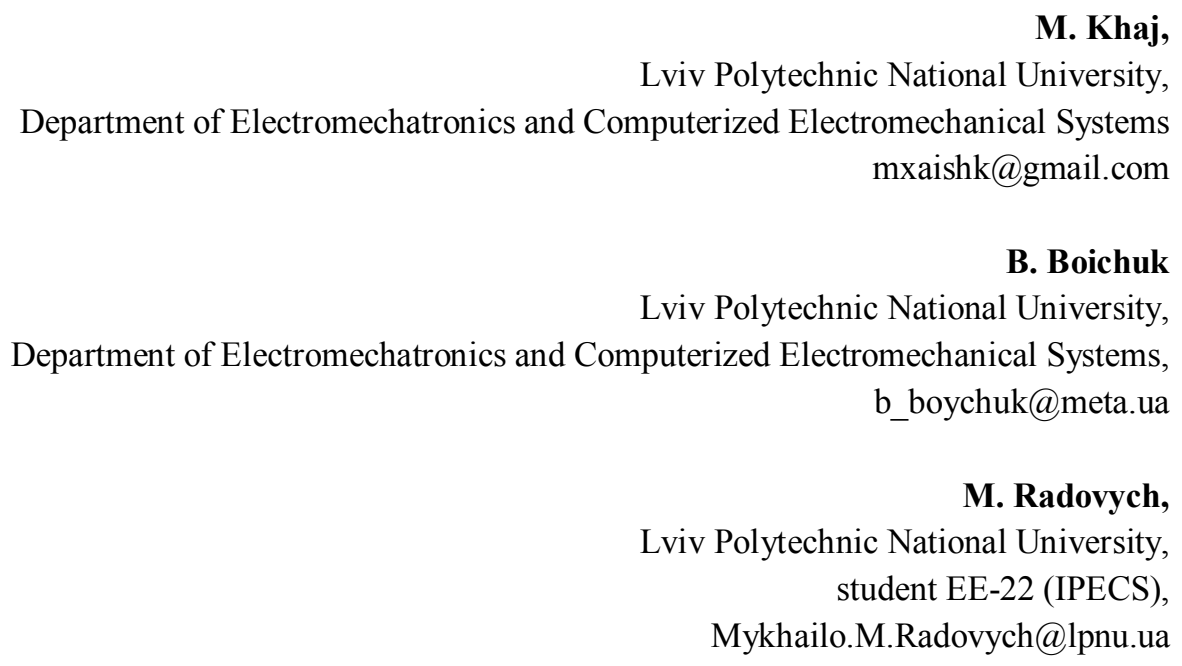

BASIC CONSTRUCTIVE RATIOS IMPULSE LINEAR GENERATOR

(C) Kharchyshyn B., Khaj M., Boichuk B., Radovych M., 2020

The sources of energy lost in an artillery shot have been analyzed. It is proposed to use the antirecoil devices energy of movement for generation, accumulation and storage in the form of electrical energy for the energy independence of the unit in course of a combat task.

For this purpose, a linear pulse generator with a smooth anchor of magnetoelectric excitation, the structure of the active part of which was investigated, was applied.

The principles of structure discretization of the electromechanical converter to the linear impulse generator were applied, which made it possible to optimally use the active materials.

The assertion is used that in the case of an unsaturated magnetic conductor, the magnetomotive force of a permanent magnet is applied mainly to the nonmagnetic gap, so the basic height criterion is 
the equality of the height of the magnet with the magnitude consisting of a winding layer thickness and the technological gap between the magnet and the surface, and the thickness of the core is equal to the total thickness of the stator's backs and slider cores.

The optimal values of the pole division rate for the specified values of the inner and outer diameters of the designed generator have been set.

The basic relations for determining the optimum values of the width and height of the magnet, the thickness of the stator core and the slider backs have been provided, taking into account the scattering coefficients and bringing the area of the magnetic core to its average diameter, which takes into account the reduction of the magnetic field due to the diameter decrease compared to the inner magnet diameter.

The ratio for determining the bore diameter of the slider is provided.

Key words: linear generator; annular permanent magnet; coil; annular winding; slider; slider magnetic thickness; stator magnetic circuit; inductor. 